\title{
The Status-Signaling Property of Self-Esteem:The Role of Self-Reported Self-Esteem and Perceived Self-Esteem in Personality Judgments
}

\author{
Virgil Zeigler-Hill,' Avi Besser, ${ }^{2}$ Erin M. Myers, ${ }^{3}$ \\ Ashton C. Southard, ${ }^{4}$ and Mallory L. Malkin ${ }^{4}$ \\ 'Oakland University \\ ${ }^{2}$ Sapir Academic College, Israel \\ ${ }^{3}$ Western Carolina University \\ ${ }^{4}$ University of Southern Mississippi
}

\begin{abstract}
Objective: The provision of information appears to be an important feature of self-esteem. The present studies examined whether self-esteem possesses a status-signaling property such that an individual's level of self-esteem is associated with how the individual is perceived by others.

Method: In Study I, trained judges watched brief videos of 157 participants and rated targets as having higher levels of self-esteem when the targets were believed to possess more positive personality characteristics. Study 2 found that participants (357 targets) were rated as having higher levels of self-esteem when they were given more positive personality evaluations by their friends and family members (I,615 perceivers).

Results: Consistent with the proposed status-signaling model, high levels of self-esteem were generally associated with the perception of positive personality characteristics.

Conclusions: These findings are discussed in the context of an extended informational model of self-esteem consisting of both the status-tracking and status-signaling properties of self-esteem.
\end{abstract}

Keywords: self-esteem, status, sociometer

The transfer of information between the individual and the social environment appears to be an important feature of selfesteem. The most widely studied informational model of selfesteem is the sociometer model that was developed by Leary and his colleagues (e.g., Leary, Tambor, Terdal, \& Downs, 1995). According to the sociometer model, self-esteem has a status-tracking property such that an individual's level of selfesteem is dependent on his or her perceived relational value. According to this model, self-esteem is analogous to a gauge that changes in accordance with perceived shifts in the degree to which the individual believes that he or she is accepted and valued by the social environment. If perceived relational value decreases, then individuals should experience a decrease in their state self-esteem that motivates them to engage in compensatory behaviors (e.g., being nicer to those in their social environment) in order to increase their relational value and, as a consequence, their self-esteem. Thus, the sociometer model suggests that people do not care about self-esteem for its own sake; rather, self-esteem is important because of what it indicates about relational value (Leary et al., 1995).
Status-tracking models of self-esteem, such as the sociometer model, represent an important advance over previous models of self-esteem that typically offered little - if anyexplanation concerning what self-esteem actually does or why it is important (Leary et al., 1995). However, status-tracking models may provide an incomplete picture of how information is transferred between the individual and the social environment because these models have neglected to account for the possibility that the individual's level of self-esteem may influence how he or she is perceived by others. That is, statustracking models of self-esteem have focused on the influence that one's perceived standing may have on self-esteem (e.g., Does greater status lead to higher self-esteem?) without addressing the possibility that one's self-esteem level may also influence how others perceive the individual (e.g., Does higher

Correspondence concerning this article should be addressed to Virgil Zeigler-Hill, Department of Psychology, Oakland University, 212A Pryale Hall, Rochester, MI 48309. Email: zeiglerh@oakland.edu. 
self-esteem lead to greater status?). The status-signaling model of self-esteem addresses the possibility that an individual's level of self-esteem may influence how that individual presents himself or herself to others and, consequently, how that individual is perceived by the social environment. According to this model, an individual's self-esteem level may influence how that person is perceived such that individuals with high self-esteem may generally be viewed more positively than those with low self-esteem. The status-signaling model of selfesteem may provide a complement to previous status-tracking models of self-esteem to allow for a more inclusive informational model of self-esteem. This extended informational model of self-esteem suggests not only that self-esteem is affected by how individuals think they are viewed by others on various dimensions (status-tracking property) but also that their level of self-esteem actually influences how others perceive them (status-signaling property). This model emphasizes the reciprocal influence of the self-esteem system and the social environment in a manner that is consistent with previous research demonstrating the dynamic interplay of perceptions between the individual and others (e.g., Madon et al., 2001).

The status-signaling model of self-esteem is derived from similar status-signaling models developed for nonhuman species. These other status-signaling models emphasize that a wide array of organisms use signals of quality to communicate information concerning their phenotypic and genetic qualities to the social environment (e.g., Anderson, 1994; Dale, Lank, \& Reeve, 2001; Grafen, 1990; Zahavi, 1975). For example, qualities such as conspicuous color traits serve as signals of dominance in a variety of species, including birds (e.g., Senar, 2006), lizards (e.g., Martin \& Forsman, 1999), and insects (e.g., Tibbetts \& Dale, 2004). These signals are advantageous to the organism providing the signal as well as others for a variety of reasons. One example is that these signals allow for the assessment of the likely outcome of conflict, which provides the opportunity for individuals to avoid unnecessary confrontations that may prove costly to one or more of the organisms involved. The use of coloration is just one of many "badges of status" that have been observed with other signals, including an array of physical characteristics (e.g., size, odor) and behaviors (e.g., vocalizations, aggressive displays; Bergman et al., 2003; Bokony, Lendvai, \& Liker, 2006; Estes, 1992; Fossey, 1983; Preuschoft, 1999). Analogous behaviors that assert one's status may be observed in humans, such as eye gaze patterns, bodily posture, assertive speech, or bodily adornment.

The inherent ambiguity of many indicators of social value among humans suggests that an individual's expressed level of self-esteem may have an influence on how that individual is viewed by the social environment. If an individual behaves as if he or she has high self-esteem, then this person may be perceived in a positive manner by others as long as there is not sufficient evidence to suggest that he or she does not possess the abilities and accomplishments that would actually warrant high self-esteem. This has been demonstrated in previous studies showing that manipulating the ostensible self-esteem level of a target influences evaluations of the target on other dimensions (Zeigler-Hill \& Besser, 2011; Zeigler-Hill \& Myers, 2009, 2011). For example, individuals who are believed to possess high self-esteem are often assumed to have other desirable characteristics, such as political competence (Zeigler-Hill \& Myers, 2009) and romantic desirability (Zeigler-Hill \& Besser, 2011; Zeigler-Hill \& Myers, 2011). These results suggest that the ability to convey signals about one's feelings of self-worth may be vitally important to forming and maintaining social relationships as well as establishing one's social standing (see Kurzban \& Aktipis, 2007, for a similar argument).

It has been previously suggested that maintaining positive self-views may influence the perceptions of other individuals (e.g., Kurzban \& Aktipis, 2007), but the present approach is novel in that this process is incorporated into an extended informational model of self-esteem. Previous research examining whether an individual's self-esteem influences how he or she is perceived by others has produced mixed results (e.g., Srivastava \& Beer, 2005). It is important to note that these previous studies were based on the assumption that one's selfesteem was readily apparent to others. This assumption may not be warranted given that self-ratings of self-esteem are only modestly associated with perceiver ratings of self-esteem (e.g., Buhrmester, Furman, Wittenberg, \& Reis, 1988; Watson, Suls, \& Haig, 2002). The lack of convergence between self- and perceiver ratings of self-esteem may be important for understanding the inconsistent findings concerning the link between an individual's feelings of self-worth and how others view the individual. That is, just as status-tracking models of selfesteem are based on the individual's perception of his or her relational value - which may or may not represent his or her actual level of social inclusion - the impact of the statussignaling property of self-esteem is going to be largely determined by perceptions of the target's level of self-esteem. In other words, the signals that are broadcast by an individual concerning his or her self-esteem will only influence the perceptions of others to the degree that these signals are received by those individuals. Consistent with this proposal, perceiver ratings of self-esteem have been found to be more strongly associated with perceiver ratings of interpersonal skill (Buhrmester et al., 1988) and personality traits (Watson et al., 2002) than were self-ratings of self-esteem.

\section{Overview and Predictions}

The primary goal of the present studies was to examine whether self-esteem was associated with how individuals are perceived by their social environments. The prediction was that self-esteem would serve as a signal of status such that higher levels of self-esteem-both self-reported and perceivedwould generally be associated with more positive qualities than lower levels of self-esteem. To examine this prediction, two studies were conducted to determine whether a target's 
level of self-esteem was associated with perceivers' ratings of the target on various dimensions of personality. In Study 1, perceivers were asked to rate unacquainted targets based only on a 3-minute video. This design was selected so that we could determine whether the self-esteem signals broadcast by individuals were strong enough to be detected despite the limited information available to the perceivers. Study 2 was designed to examine how the self-esteem levels of targets were associated with how they were perceived by those who knew them well (i.e., friends and family members). The goal of Study 2 was to extend the results of Study 1 by using perceivers who were acquainted with the targets in order to increase the amount of information about the targets that was available to the perceivers.

\section{STUDY I: RATINGS OF TARGETS BASED ON A BRIEF VIDEO}

The purpose of Study 1 was to determine whether a target's level of self-esteem was associated with the evaluations provided by perceivers who did not know the target. More specifically, the present study asked trained raters (i.e., perceivers) to watch brief videos of participants (i.e., targets) and complete evaluations of the targets' self-esteem level and personality based only on this limited information. Our prediction was that targets possessing higher levels of self-esteem would be evaluated more positively than those who possessed lower levels of self-esteem.

\section{Method}

\section{Participants and Procedure}

Participants were 157 undergraduates (35 men and 122 women) at a university in the southern region of the United States who were enrolled in psychology courses and participated in return for partial fulfillment of a research participation requirement. The mean age of the targets was 20.07 years $(S D=3.96)$, and their racial/ethnic composition was $52 \%$ White, 44\% Black, 2\% Hispanic, and 2\% Other. Participants attended a laboratory session during which they completed measures of self-esteem and personality features before making a 3-minute video describing themselves to potential romantic partners as part of a dating service simulation. The participants in these videos were then rated independently by seven trained undergraduate research assistants (2 men, 5 women) with regard to their perceived self-esteem and personality features. The research assistants were blind to the selfreported self-esteem levels and personality features of the participants.

\section{Measures Completed by the Targets}

Self-reported self-esteem level. The self-esteem level of the targets was measured using the Rosenberg Self-Esteem Scale
(Rosenberg, 1965), which is a 10-item measure of global selfesteem (e.g., "On the whole, I am satisfied with myself"). Participants were instructed to complete the instrument according to how they typically or generally feel about themselves. Responses were made on a scale ranging from 1 (strongly disagree) to 5 (strongly agree). This instrument is regarded as a well-validated and reliable measure of global self-regard (e.g., Blaskovich \& Tomaka, 1991). The internal consistency of this measure for the present study was $\alpha=.87$.

Self-reported personality features. The personality features of the targets were measured using the Big Five Inventory (John \& Srivastava, 1999), which is a 44-item measure of the Big Five dimensions of personality: Extraversion (eight items; e.g., "I see myself as someone who is talkative"; $\alpha=.83$ ), Agreeableness (nine items; e.g., "I see myself as someone who is helpful and unselfish with others"; $\alpha=.78$ ), Conscientiousness (nine items; e.g., "I see myself as someone who makes plans and follows through with them"; $\alpha=.77$ ), Emotional Stability (eight items; e.g., "I see myself as someone who is relaxed, handles stress well"; $\alpha=.79)$, and Openness (10 items; e.g., "I see myself as someone who is curious about many different things"; $\alpha=.73$ ). Responses were made on a scale ranging from 1 (strongly disagree) to 5 (strongly agree). This instrument is regarded as a well-validated and reliable measure of personality (e.g., Soto \& John, 2009).

\section{Measures Completed by the Perceivers}

Perceived self-esteem level. The perceived self-esteem levels of the targets were assessed using modified versions of the Single-Item Self-Esteem Scale (Robins, Hendin, \& Trzesniewski, 2001) and the State Self-Esteem Scale (Heatherton \& Polivy, 1991). The Single-Item Self-Esteem Scale measures global self-esteem using only a single item (i.e., "I see the target as someone who has high self-esteem"), and responses were made on a scale ranging from 1 (strongly disagree) to 5 (strongly agree). The State Self-Esteem Scale is a 20-item measure that assesses perceived self-esteem across three domains: Performance (seven items; e.g., "The target appears to feel confident about his/her abilities"; $\alpha=.80$ ), Social (seven items; e.g., "The target appears to feel concerned about the impression he/she is making" [reverse-scored]; $\alpha=.83$ ), and Appearance (six items; e.g., "The target feels satisfied with the way his/her body looks right now"; $\alpha=.79$ ). Responses for the State Self-Esteem Scale were made on a scale ranging from 1 (not at all) to 5 (extremely). A composite measure of perceived self-esteem was calculated that consisted of the standardized scores from these measures $(\alpha=.87)$.

Perceived personality features. The Ten-Item Personality Inventory (Gosling, Rentfrow, \& Swann, 2003) was used to capture the perceived personality characteristics of the targets. The Ten-Item Personality Inventory assesses the Big Five personality dimensions: Extraversion $(\mathrm{ICC}=.89)$, Agreeableness 
$(\mathrm{ICC}=.71)$, Conscientiousness $(\mathrm{ICC}=.78)$, Emotional Stability $(\mathrm{ICC}=.74)$, and Openness ( $\mathrm{ICC}=.68)$. Respondents were asked to rate how well each pair of adjectives (e.g., extraverted, enthusiastic) described the targets using a scale that ranged from 1 (strongly disagree) to 7 (strongly agree).

\section{Results}

Descriptive statistics and correlations are presented in Table 1. To correct for the number of analyses, we only considered those effects for which $p<.01$ to be statistically significant. The correlation between self-reported self-esteem and perceived self-esteem was $r=.32, p<.001$. This suggests a significant level of self-other agreement such that the judges were able to detect the self-esteem signals emitted by the targets with some degree of accuracy, but the modest nature of the correlation suggests that the reception of the self-esteem signal was far from perfect. The only other significant correlations between self-reported personality features and perceived personality features emerged for Extraversion $(r=.49, p<.001)$ and Openness $(r=.27, p<.001)$. The lack of self-other agreement for Agreeableness, Conscientiousness, and Emotional Stability may have been due, at least in part, to the limited information available to the judges.

To determine whether the self-esteem levels of the targets were associated with perceiver ratings when the perceivers had relatively little information about the targets, we conducted a hierarchical multiple regression analysis in which the per- ceiver ratings of each target's self-esteem were regressed onto the target's self-reported self-esteem, the target's self-reported personality features, and the perceived personality features of the target. The main effect terms representing self-reported self-esteem and self-reported personality features were entered on Step 1, and the terms representing the perceived personality features of the targets were entered on Step $2 .{ }^{1}$

The results of this analysis found that the only self-reported features to emerge as significant predictors of perceiver ratings of the target's self-esteem were self-reported self-esteem $(\beta=.23, t=2.74, p<.01, d=.46)$ and self-reported Extraversion $(\beta=.25, t=2.98, p<.01, d=.49)$. This suggests that individuals are perceived as having high levels of self-esteem when they report feeling good about themselves and when they view themselves as being extraverted. The target's selfreported self-esteem and self-reported personality features explained a significant percentage of the variance in perceived self-esteem $\left(R^{2}=.19, p<.001\right)$. In addition to these selfreported predictors, four of the five perceiver ratings of personality reached conventional levels of significance in Step 2 of this analysis: perceived Extraversion $(\beta=.40, t=5.84$, $p<.001, \quad d=.99)$, perceived Agreeableness $(\beta=-.39$, $t=-6.56, p<.001, d=-1.11$ ), perceived Conscientiousness $(\beta=.27, t=3.93, p<.001, d=.66)$, and perceived Emotional Stability $(\beta=.46, t=7.37, p<.001, d=1.25)$. That is, targets were perceived to have higher levels of self-esteem when they were viewed by the judges as being extraverted, disagreeable, conscientious, and emotionally stable. The inclusion of per-

Table I Study I: Intercorrelations and Descriptive Statistics for Self-Reported Self-Esteem, Self-Reported Personality Features, Perceived SelfEsteem, and Perceived Personality Features

\begin{tabular}{|c|c|c|c|c|c|c|c|c|c|c|c|c|}
\hline I. Self-Reported Self-Esteem (Target) & - & & & & & & & & & & & \\
\hline 2. Self-Reported Extraversion (Target) & $.36 * * *$ & - & & & & & & & & & & \\
\hline $\begin{array}{l}\text { 4. Self-Reported Conscientiousness } \\
\text { (Target) }\end{array}$ & $.31 * * *$ & .15 & $.23 * *$ & - & & & & & & & & \\
\hline 6. Self-Reported Openness (Target) & .12 & $.26 * * *$ & .14 & .02 & .15 & - & & & & & & \\
\hline 7. Perceived Self-Esteem (Judges) & $.32 * * *$ & $.33 * * *$ & .02 & .08 & $.22 * *$ & .19 & - & & & & & \\
\hline 8. Perceived Extraversion (Judges) & $.22 * *$ & $.49 * * *$ & .08 & -.03 & .06 & .06 & $.67 * * *$ & - & & & & \\
\hline 9. Perceived Agreeableness (Judges) & -.05 & -.06 & -.02 & .04 & -.11 & .03 & .07 & -.01 & - & & & \\
\hline $\begin{array}{l}\text { 10. Perceived Conscientiousness } \\
\text { (Judges) }\end{array}$ & .07 & .06 & .07 & .15 & .02 & .16 & $.39 * * *$ & .09 & $.67 * * * *$ & - & & \\
\hline Mean & 4.18 & 3.53 & 4.09 & 3.66 & 3.19 & 3.56 & 0.00 & 3.30 & 3.93 & 3.94 & 3.95 & 3.28 \\
\hline Standard deviation & 0.73 & 0.87 & 0.66 & 0.76 & 0.86 & 0.67 & 1.00 & 0.89 & 0.43 & 0.50 & 0.43 & 0.62 \\
\hline Theoretical range of scores & $\mathrm{I}-5$ & $\mathrm{I}-5$ & $\mid-5$ & $1-5$ & $\mathrm{I}-5$ & $\mathrm{I}-5$ & $-^{\mathrm{a}}$ & $1-7$ & I-7 & I-7 & I-7 & $\mathrm{I}-7$ \\
\hline
\end{tabular}

Note. Convergent correlations are presented in boldface.

${ }^{a}$ The theoretical range for perceived self-esteem is technically infinite because it is a standardized composite score. However, the observed scores for this measure ranged from -1.84 to 1.71 .

$* * p<.01$. *** $p<.001$. 
ceived personality features in the model significantly increased the percentage of variance in perceived self-esteem that was explained $\left(R^{2}=.76, p<.001 ; \Delta R^{2}=.57, p<.001\right)$.

Additional regression analyses were conducted in order to gain a better understanding of the shift that emerged in the association between perceived Agreeableness and perceived self-esteem from their zero-order correlation (no significant association) to the regression analysis (a significant negative association). The first follow-up analysis only included the perceived personality features as predictors in the model to determine whether it was the overlap in these variables that led to the emergence of the negative association between perceived Agreeableness and perceived self-esteem. In this model, perceived Agreeableness had a negative association with perceived self-esteem $(\beta=-.42, t=-6.94, p<.001$, $d=-1.14$ ) that was similar in magnitude to the association observed in the full model. The second follow-up analysis included perceived Agreeableness, self-reported self-esteem, and self-reported personality features as predictors of perceived self-esteem but did not include the other perceived personality features. In this analysis, perceived Agreeableness was not associated with perceived self-esteem $(\beta=.11$, $t=1.46, n s)$. Taken together, these results suggest that the negative association that was observed between perceived Agreeableness and perceived self-esteem in the full regression model was due to the overlap between perceived Agreeableness and the other perceived personality features.

\section{Discussion}

The association between self-reported self-esteem and perceived self-esteem emerged in Study 1, which suggests that the self-esteem levels of targets can be discerned even when the amount of information that perceivers have about the targets is extremely limited. This correlation was not particularly strong, which suggests that self-esteem signals may not be received with sufficient clarity in situations in which very limited information is available to the perceiver. However, it is important to note that the self-other agreement for self-esteem was similar in magnitude to what was observed for Extraversion and Openness, and it was greater than the convergence observed for the other personality features. Self-reported Extraversion was associated with perceived self-esteem, which is not terribly surprising given that Extraversion is a characteristic that is easily perceived by others (e.g., Blackman \& Funder, 1998) and that it has been found to be associated with self-esteem in past research (e.g., Watson et al., 2002). One reason for the connection between Extraversion and perceived self-esteem may be the fact that Extraversion is intimately tied with agentic interpersonal behavior (i.e., social dominance), which has been shown to be associated with self-esteem (Zeigler-Hill, 2010; Zeigler-Hill, Clark, \& Beckman, 2011). Agentic interpersonal behavior often involves exercising power over others in social contexts, and people who engage in this sort of social behavior tend to describe themselves as forceful, assertive, and self-confident (Wiggins, 1995). The social dominance that typically accompanies Extraversion may serve various selfesteem regulation functions, such as maintaining and enhancing feelings of self-worth as well as communicating these attitudes about the self to the social environment. This pattern is consistent with previous arguments that self-esteem may be associated with relative positions in dominance hierarchies (e.g., Kirkpatrick \& Ellis, 2001).

Perceived self-esteem was positively associated with perceived Extraversion, Conscientiousness, and Emotional Stability. Taken together, these results suggest that the perceivers believed that individuals who were extraverted, conscientious, and emotionally stable possessed higher levels of self-esteem. It is important to note that these associations emerged after controlling for self-reported personality features. This is important because it shows that the connections between selfesteem and these personality features were not simply due to the actual personality features possessed by the targets. Perceived Agreeableness had a more complex association with perceived self-esteem than was found for the other personality features. The zero-order correlation between perceived Agreeableness and perceived self-esteem failed to reach conventional levels of significance, but a significant negative association emerged between these variables in the regression analysis that included the other personality features. Further exploration of this effect found that the negative association between perceived Agreeableness and perceived self-esteem was more likely due to the inclusion of the other perceived personality features in the model rather than the self-reported features of self-esteem and personality. This suggests the intriguing possibility that perceived personality features may act as mutual suppressors under certain conditions (Paulhus, Robins, Trzesniewski, \& Tracy, 2004). That is, including features of personality that overlap with each other to some degree (e.g., perceived Agreeableness and perceived Conscientiousness) may alter their associations with other variables. In essence, controlling for the other perceived personality features may allow for a better understanding of the unique connection between perceived Agreeableness and perceived self-esteem that is not simply the result of a generally positive view of the target. This suppression effect may explain why the negative association between perceived Agreeableness and perceived self-esteem only emerged when the other personality features were included in the analysis because this approach accounted for the overlap that these other perceived personal features had with perceived Agreeableness.

The covariation between perceived self-esteem and perceived personality features is consistent with the implicit theory of self-esteem, which argues that simply believing someone has high (or low) levels of self-esteem may alter perceptions of the individual on other dimensions related to self-esteem (Zeigler-Hill \& Besser, 2011; Zeigler-Hill \& Myers, 2009, 2011). It is not surprising that high levels of self-esteem were believed to accompany Extraversion, Conscientiousness, and Emotional Stability, but the connection 
between high self-esteem and low levels of Agreeableness was not expected. It has been argued that narcissistic individuals are "disagreeable extraverts" (Paulhus, 2001), but this term has not been applied to those with high levels of self-esteem. In fact, individuals with high self-esteem often describe themselves as being relatively agreeable (Campbell, Rudich, \& Sedikides, 2002), and their self-reported interpersonal style is often at least somewhat communal (Zeigler-Hill, 2010; Zeigler-Hill et al., 2011). It is possible that individuals who are perceived as having high levels of self-esteem may be thought to be somewhat narcissistic, which may explain the negative association between perceived self-esteem and perceived Agreeableness that emerged when other personality features were controlled.

\section{STUDY 2: RATINGS OF TARGETS BY FRIENDS AND FAMILY MEMBERS}

The purpose of Study 2 was to extend the results of Study 1 by using perceivers who were acquainted with the targets in order to determine whether the self-reported and perceived selfesteem levels of the targets would be associated with perceiver ratings of personality when the perceivers had more information about the targets. This was accomplished by asking participants to complete measures of self-esteem and personality features before recruiting friends and family members to evaluate their self-esteem and personality characteristics. Our prediction was that the self-esteem levels of the targets would be associated with their perceived personality features even when accounting for their self-reported personality features. The rationale for this prediction was that the perceivers in Study 2 would have access to more information about the targets than the judges in Study 1, so the self-esteem signals that were broadcast by the targets would be more clearly received by the perceivers and would be more strongly associated with ratings on other dimensions.

\section{Method}

\section{Participants and Procedure}

Participants were 930 undergraduates at a university in the southern region of the United States who were enrolled in psychology courses and participated in return for partial fulfillment of a research participation requirement. Participants completed measures of self-esteem level and personality features during an online prescreening session at the beginning of the semester. These participants were offered additional research credit in exchange for recruiting up to five friends or family members (i.e., perceivers) to complete questionnaires concerning the participant (i.e., the target) via the Internet. To assess the manner in which individuals with different levels of self-esteem were viewed by others, we had to establish some minimum number of perceivers for each target in order for them to be included in the final analyses. As a result, we decided to only include targets in the final analyses who recruited three or more perceivers (see Malkin, Zeigler-Hill, Barry, \& Southard, in press, for a similar strategy). Of the 930 participants who completed the initial questionnaires, 357 participants (58 men and 299 women) recruited three or more perceivers to participate in the study by completing questionnaires about their perceptions of the targets who recruited them ( $38 \%$ of the original sample). The mean age of the targets was 20.73 years $(S D=4.78)$, and their racial/ethnic composition was $58 \%$ White, $36 \%$ Black, $2 \%$ Hispanic, and $4 \%$ Other. The targets for our analyses did not differ from those participants who did not recruit three or more perceivers in terms of age, $t=1.57, n s$; racial/ethnic background, $\chi^{2}(6)=5.07, n s$; or selfesteem, $t<1, n s$. However, women were more likely than men to recruit three or more perceivers, which resulted in women being more likely than men to be included in the final analyses, $\chi^{2}(1)=7.11, p<.01$. The 357 targets recruited a total of 1,615 perceivers (541 men and 1,074 women), with an average of 4.52 perceivers for each target. Perceivers were allowed to submit only one rating for a single participant (i.e., the same perceiver could not provide ratings for more than one target). The mean age of the perceivers was 27.43 years $(S D=12.34)$, and their racial/ethnic composition was $60 \%$ White, $35 \%$ Black, 2\% Hispanic, and 3\% Other. The targets recruited perceivers who were generally older than themselves $\left(M_{\text {targets }}\right.$ $=20.73$ years; $M_{\text {perceivers }}=27.43$ years; $\left.t=26.50, p<.001\right)$, and the perceivers were more likely than the targets to be male ( $16 \%$ of targets but $33 \%$ of perceivers), $\chi^{2}(1)=41.15$, $p<.001$. However, the targets and the perceivers were similar in terms of their racial/ethnic composition, $\chi^{2}(6)=8.31$, ns.

\section{Measures Completed by the Targets}

Self-reported self-esteem level. As in Study 1, the Rosenberg Self-Esteem Scale (Rosenberg, 1965) was used to measure the self-esteem level of each target $(\alpha=.90)$.

Self-reported personality features. As in Study 1, the Big Five Inventory (John \& Srivastava, 1999) was used to measure the following personality features of each target: Extraversion $(\alpha=.77)$, Agreeableness $(\alpha=.78)$, Conscientiousness ( $\alpha=.75)$, Emotional Stability $(\alpha=.78)$, and Openness $(\alpha=.75)$.

\section{Measures Completed by the Perceivers}

Perceived self-esteem. The perceived self-esteem levels of the targets were assessed using a composite of the modified Single-Item Self-Esteem Scale (Robins et al., 2001) and the State Self-Esteem Scale (Heatherton \& Polivy, 1991) that were used for the same purpose in Study 1.

Perceived personality. As in Study 1, a modified version of the Ten-Item Personality Inventory (Gosling et al., 2003) was 
used to capture the perceived personality characteristics of the targets for Extraversion, Agreeableness, Conscientiousness, Emotional Stability, and Openness.

\section{Results}

Descriptive statistics and correlations are presented in Table 2. As in Study 1, we only considered those effects for which $p<.01$ to be statistically significant in order to correct for the number of analyses. The correlation between selfreported self-esteem and perceived self-esteem was $r=.44$, $p<.001$, which suggests that the self-esteem levels of targets could be detected by others. Significant levels of self-other agreement also emerged for each of the personality features $(r \mathrm{~s}>.29, p \mathrm{~s}<.001)$. The greater convergence of self-other ratings in Study 2 is most likely due to perceivers in this study having much greater knowledge about the targets than was the case in Study 1. Self-reported selfesteem was associated with the following perceived personality features: Extraversion $(r=.16, p<.01)$, Agreeableness $(r=.18, p<.001)$, Conscientiousness $(r=.20, p<.001)$, and Emotional Stability $(r=.30, p<.001)$. This suggests that individuals who feel good about themselves are viewed more positively than individuals with lower levels of self-esteem.

\section{Data Analytic Strategy}

The present analyses had three goals that map directly onto our hypotheses. The first goal was to examine the covariation between perceiver ratings of self-esteem and perceiver ratings of personality. The second goal was to determine whether self-reported levels of self-esteem were associated with perceived self-esteem and perceived personality features. The data from the present study comprised a multilevel data structure because observations at one level of analysis were nested within another level of analysis (i.e., perceiver ratings were nested within targets). More specifically, this was a one-withmany design (see Marcus, Kashy, \& Baldwin, 2009, for a review) in which each target was evaluated by multiple perceivers. A multilevel model using the program HLM (Bryk, Raudenbush, \& Congdon, 1998) was employed to analyze these data due to this hierarchical structure. This approach is necessary to account for the violation of the independence assumption that occurs as a result of using multiple perceivers for each target. At a conceptual level, this multilevel model involved two steps. The first step (the across-targets level) examined whether the perceiver ratings of the targets differed between targets depending on their self-reported characteristics (e.g., "Was perceived self-esteem higher for those targets who described themselves as being extraverted?"). The second step (the among-perceivers level) examined the association

Table 2 Study 2: Intercorrelations and Descriptive Statistics for Self-Reported Self-Esteem, Self-Reported Personality Features, Perceived SelfEsteem, and Perceived Personality Features

\begin{tabular}{|c|c|c|c|c|c|c|c|c|c|c|c|c|}
\hline & I & 2 & 3 & 4 & 5 & 6 & 7 & 8 & 9 & 10 & 11 & 12 \\
\hline $\begin{array}{l}\text { I. Self-Reported Self-Esteem } \\
\text { (Target) }\end{array}$ & - & & & & & & & & & & & \\
\hline $\begin{array}{l}\text { 2. Self-Reported Extraversion } \\
\text { (Target) }\end{array}$ & $.25 * * *$ & - & & & & & & & & & & \\
\hline $\begin{array}{l}\text { 3. Self-Reported Agreeableness } \\
\text { (Target) }\end{array}$ & $.26 * * *$ & $.17^{* *}$ & - & & & & & & & & & \\
\hline $\begin{array}{l}\text { 4. Self-Reported Conscientiousness } \\
\text { (Target) }\end{array}$ & $.38 * * *$ & $.21 * * *$ & $.52 * * *$ & - & & & & & & & & \\
\hline $\begin{array}{l}\text { 5. Self-Reported Emotional Stability } \\
\text { (Target) }\end{array}$ & $.37 * * *$ & $.23 * * *$ & $.39 * * *$ & $.35 * * *$ & - & & & & & & & \\
\hline 6. Self-Reported Openness (Target) & .09 & $.21 * * *$ & $.29 * * *$ & $.15 * *$ & .12 & - & & & & & & \\
\hline 7. Perceived Self-Esteem (Judges) & $.44 * * *$ & $.24 * * *$ & $.23 * * *$ & $.34 * * *$ & $.4 I^{* * *}$ & $.17^{* * * *}$ & - & & & & & \\
\hline 8. Perceived Extraversion (Judges) & $.16 * *$ & $.58 * * *$ & .07 & .09 & .10 & .08 & $.37 * * *$ & - & & & & \\
\hline 9. Perceived Agreeableness (Judges) & $.18 * * *$ & -.07 & $.33 * * *$ & $.25 * * *$ & $.20 * * *$ & .06 & $.37 * * *$ & .05 & - & & & \\
\hline $\begin{array}{l}\text { 10. Perceived Conscientiousness } \\
\text { (Judges) }\end{array}$ & $.20 * * *$ & -.03 & $.16 * *$ & $.44 * * *$ & .10 & -.03 & $.51 * * *$ & $.21 * * *$ & $.53 * * *$ & - & & \\
\hline $\begin{array}{l}\text { II. Perceived Emotional Stability } \\
\text { (Judges) }\end{array}$ & $.30 * * *$ & .04 & $.26 * * *$ & $.21 * * *$ & $.48 * * *$ & .09 & $.53 * * *$ & $.14 * *$ & $.59 * * *$ & $.41 * * *$ & - & \\
\hline 12. Perceived Openness (Judges) & .10 & $.15^{* *}$ & $.21 * * *$ & $.20 * * *$ & .13 & $.29 * * *$ & $.48^{* * *}$ & $.35 * * *$ & $.44 * * *$ & $.46 * * *$ & $.37 * * *$ & 一 \\
\hline Mean & 4.09 & 3.28 & 3.82 & 3.55 & 3.09 & 3.40 & 0.00 & 4.77 & 5.11 & 5.41 & 4.74 & 5.20 \\
\hline Standard deviation & 0.80 & 0.74 & 0.66 & 0.59 & 0.69 & 0.61 & 1.00 & 1.08 & 0.93 & 0.99 & 1.02 & 0.87 \\
\hline Theoretical range of scores & $1-5$ & $\mathrm{I}-5$ & $\mathrm{I}-5$ & $\mathrm{I}-5$ & $\mathrm{I}-5$ & $\mathrm{I}-5$ & $-^{\mathrm{a}}$ & I-7 & $\mathrm{I}-7$ & I-7 & I-7 & $\mathrm{I}-7$ \\
\hline
\end{tabular}

Note. Convergent correlations are presented in boldface.

a The theoretical range for perceived self-esteem is technically infinite because it is a standardized composite score. However, the observed scores for this measure ranged from -1.57 to 1.54 .

$* * p<.01$. *** $p<.001$. 
between the ratings provided by the perceivers (e.g., "Do perceivers rate targets as having higher levels of self-esteem when they believe these targets are more extraverted?").

\section{The Association That Perceived Self-Esteem Has With Self-Reported Self-Esteem, Self-Reported Personality Features, and Perceived Personality Features}

A two-level model was used to examine the relationship that perceiver ratings of the targets' self-esteem had with the selfreported self-esteem of the target, the self-reported personality features of the target, and the perceived personality features of the targets. For these analyses, the perceiver ratings were group-mean centered with group defined as the perceivers who shared a common target (Raudenbush \& Bryk, 2002). This technique was used because there was considerable variability in the ratings between perceivers (e.g., some perceivers rated their target as more extraverted than other perceivers who rated the same target) and across targets (e.g., some targets were generally rated as more extraverted than other targets). The use of group-mean centering for perceiver ratings eliminated the influence of these differences on parameter estimates and allowed us to examine the association between perceived selfesteem and deviations from the average perception of the target's personality features (e.g., "Do perceivers rate targets as having higher levels of self-esteem when they rate the target as more extraverted than is typical for that target?").

The first step of this analysis included self-reported selfesteem and self-reported personality features as predictors of perceived self-esteem. In essence, these analyses were focused on the extent to which others could detect the self-esteem levels of the targets (e.g., "Are the targets who report higher levels of self-esteem viewed by others as feeling good about themselves?"). This type of analysis is referred to as a means as outcomes analysis (Bryk \& Raudenbush, 1992). The selfreported self-esteem levels of the targets were associated with their perceived self-esteem $(B=.38, t=4.56, p<.001$, $d=.50)$ such that targets who reported possessing more positive attitudes about themselves were viewed by others as possessing more positive feelings of self-worth. The following self-reported personality features were also associated with the perceiver ratings of the self-esteem levels of the targets: Extraversion $(B=.22, t=2.68, p<.01, d=.29)$, Agreeableness $(B=-.22, t=-2.69, p<.01, d=-.30)$, Conscientiousness $(B=.23, t=2.87, p<.01, d=.32)$, and Emotional Stability $(B=.25, t=2.96, p<.001, d=.33)$. These results suggest that targets who view themselves as being extraverted, disagreeable, conscientious, and emotionally stable tend to be seen by others as possessing high levels of self-esteem. The self-reported self-esteem and personality features explained a significant percentage of the variance associated with perceived self-esteem $\left(R^{2}=.30, p<.001\right)$.

In the second step, perceived personality features were added to this model. The following perceived personality fea- tures were found to be associated with perceived self-esteem: perceived Extraversion $(B=.14, t=2.50, p<.01, d=.27)$, perceived Conscientiousness $(B=.23, t=3.28, \quad p<.001$, $d=.36)$, perceived Emotional Stability $(B=.28, t=5.05$, $p<.001, d=.55)$, and perceived Openness $(B=.14, t=2.49$, $p<.01, d=.27)$. These results suggest that targets are believed to possess more positive feelings of self-worth when they appear to be extraverted, conscientious, emotionally stable, and open to experience. Perceived Agreeableness was the only personality feature that was not associated with perceived selfesteem. The inclusion of perceived personality features increased the percentage of variance in perceived self-esteem that was explained by the model $\left(R^{2}=.81, p<.001 ; \Delta R^{2}=.51\right.$, $p<.001)$.

\section{Discussion}

The self-reported self-esteem levels and the perceived selfesteem levels of the targets were found to be associated with how the targets were rated in terms of their personality features. More specifically, higher levels of self-esteem generally accompanied more positive personality ratings. These results are consistent with the status-signaling model because they show that the perceived self-esteem levels of the targets were associated with how they were viewed by their friends and family members. The associations involving perceived selfesteem were stronger than those concerning self-reported selfesteem, which is not surprising given that the status-signaling model suggests that signals broadcast by the individual will only be associated with perceptions of the individual on other dimensions to the extent that the signal is received by the perceivers. These findings show that self-esteem-both selfreported self-esteem and perceived self-esteem - is associated with perceived personality features even when self-reported personality features are taken into account.

Although the results of Study 2 were similar to those of Study 1, these results were not identical. For example, the zero-order correlation between perceived Agreeableness and perceived self-esteem was significant in Study $2(r=.37$, $p<.001)$, but this association did not emerge in the multilevel analysis that included the other perceived personality features $(\beta=.02, t<1, n s)$. This pattern of results is quite different from the pattern that emerged in Study 1 (i.e., perceived Agreeableness did not have a significant zero-order correlation with perceived self-esteem, but it did have a significant negative association with perceived self-esteem in the regression analysis that included the other perceived personality features). One possible explanation for the differences that emerged between these studies is the amount of information about the targets that was available to the perceivers. Previous research has shown that perceivers often make very fast judgments concerning the Agreeableness of targets, but these judgments sometimes suffer from low accuracy (see Ames \& Bianchi, 2008 , for a review). It has been suggested that the reason individuals place such importance on perceived Agreeableness 
is that this feature of personality may help structure and describe social interactions by suggesting who is likely to be cooperative and reciprocate positive behaviors (e.g., Buss, 1996). It is possible that the connection between perceived Agreeableness and perceived self-esteem may shift over the course of a relationship as perceivers learn more about the target.

\section{GENERAL DISCUSSION}

Self-esteem is believed to serve as a conduit for the transfer of information between the individual and the social environment. Whereas previous informational models of self-esteem have focused primarily on the status-tracking property of selfesteem, the purpose of the present studies was to examine whether self-esteem may also have a status-signaling property such that an individual's level of self-esteem is associated with how he or she is perceived by others. The results of the present studies were generally consistent with the proposed statussignaling property of self-esteem such that individuals were viewed more positively when they possessed higher levels of self-esteem or were at least thought to possess higher levels of self-esteem. Study 1 found that higher levels of perceived self-esteem were associated with positive ratings on various personality dimensions, whereas self-reported self-esteem was only associated with perceived Extraversion. This pattern of results may have been due to the fact that perceivers in Study 1 only had access to the limited information that could be gleaned from a 3-minute video of the target. In contrast, Study 2 found that both self-reported self-esteem and perceived selfesteem were associated with more positive evaluations on various dimensions by their friends and family members. The difference in the results between the two studies is most likely due to the amount of information about the targets that was available to the perceivers. The perceivers in Study 2 had access to considerably more information about the targets because they actually knew these individuals, whereas the perceivers in Study 1 only had access to a brief video of the target.

The status-signaling model of self-esteem has a number of implications for the understanding of self-esteem. The present results underscore that the provision of information may be an important element of self-esteem. In the case of the statussignaling property of self-esteem, it is believed that the flow of information moves from the individual to the social environment such that one's level of self-esteem affects how the individual is perceived by others. The present findings suggest that perceived self-esteem may play a more important role in interpersonal phenomena than is commonly recognized. Further, the status-signaling model of self-esteem may explain why individuals are motivated to maintain and enhance their feelings of self-worth. For example, previous research has often found that individuals are motivated to restore their selfesteem following potential threats using a diverse array of mechanisms, many of which have nothing to do with the initial threat (see Tesser, 2001, for a review). Further, recent research has shown that narcissistic individuals intentionally inflate their self-reported feelings of self-worth (Myers \& ZeiglerHill, 2012). The fact that individuals restore their self-esteem using means unrelated to the initial threat and distort their self-esteem is difficult to explain using status-tracking models of self-esteem. If the sole function of self-esteem is to track one's status on certain dimensions, then behaviors such as lying about one's self-esteem would be analogous to running low on fuel in your car and manually adjusting the fuel gauge rather than stopping to get fuel (Pyszczynski, Greenberg, Solomon, Arndt, \& Schimel, 2004). According to statustracking models, self-esteem should not be the focus of restorative efforts; rather, these efforts should be directed toward those dimensions on which self-esteem is based (e.g., relational value). In contrast, the tendency for some individuals to distort their feelings of self-worth can be easily explained by the status-signaling model of self-esteem. If selfesteem serves as a signal to others concerning how individuals should be perceived, then the desire to manage how others perceive them may explain why individuals sometimes distort their apparent feelings of self-worth. It is important to note that the status-signaling model is not intended to compete with other models concerning self-esteem, such as the sociometer model (Leary et al., 1995) or terror management theory (Pyszczynski et al., 2004). Rather, the status-signaling model is merely intended to draw attention to a property of selfesteem that has been largely overlooked without discounting the status-tracking or anxiety-buffering properties of selfesteem that have been identified in previous research.

The present studies had a number of strengths, which include the use of large samples and different methodologies to capture the status-signaling property of self-esteem. However, it is also important to acknowledge some of the limitations of the present studies. First, we were unable to clearly determine whether an individual's level of self-reported self-esteem causes others to develop a particular view of the individual due to the correlational nature of the data in the present studies. Previous research has shown that manipulating the ostensible self-esteem levels of a target influences how perceivers view the target (Zeigler-Hill \& Besser, 2011; Zeigler-Hill \& Myers, $2009,2011)$. However, the purpose of the present studies was to determine whether the way that perceivers viewed the targets would be associated with the self-reported self-esteem levels of the targets rather than manipulating their self-esteem levels. Second, the present studies relied on a single self-report measure of self-esteem. Although the Rosenberg Self-Esteem Scale (Rosenberg, 1965) is the most widely used measure of self-esteem, there are other measures that capture domainspecific aspects of self-esteem that may have been useful (e.g., State Self-Esteem Scale; Heatherton \& Polivy, 1991). Third, it may be important for future research concerning the statussignaling model to consider the distinction between secure and fragile high self-esteem, given that high self-esteem is a heterogeneous construct (see Kernis, 2003, for a review). For example, the signals broadcast by individuals with secure high 
self-esteem may be quite different from those emitted by those who possess the fragile form of high self-esteem. It is possible that the connection between self-reported self-esteem and perceived self-esteem may be especially strong for those with secure high self-esteem. Fourth, the generalizability of the present findings may be limited due to our reliance on undergraduate participants. The relative youth of our targets may have limited their ability to clearly convey their feelings of self-worth to others, which may have made it more difficult for perceivers to accurately receive the signals the targets were attempting to broadcast. As a result, it is unclear whether similar patterns would emerge for older individuals who may have more experience and may be more skilled in communicating their feelings of self-worth to others.

The present studies suggest a number of possible avenues for future research. One set of questions concerns the specific behavioral indicators that individuals use to broadcast their feelings of self-worth to the members of their social environment (e.g., direct eye contact, speaking assertively). For example, Tracy and Robins (2007) have found that the feeling of pride has a distinct nonverbal expression (i.e., expanded posture, head tilted back, and arms extended away from the body) and that the expression of pride can influence the perceptions of others (Shariff \& Tracy, 2009). Verbal and nonverbal signals of self-esteem are likely to be complex, but the approach used to examine the behavioral manifestation of pride could provide valuable information concerning the interpersonal transmission of self-esteem. Another important avenue for future research concerns the ability of individuals to manage the impressions that others form concerning one's level of self-esteem. It is possible that individuals may attempt to manipulate their perceived level of self-esteem in order to deceive others about their status. Although individuals tend to believe the claims to status made by other individuals (e.g., Goffman, 1959; Jones \& Nisbett, 1971), it may improve individuals' ability to deceive others about their level of selfesteem if they actually believe their own inflated self-esteem (Trivers, 1991). That is, it may be easier to convince others that you have high self-esteem if you actually believe it yourself. It appears that the deceptive elements of the status-signaling property of self-esteem may have implications for understanding the intrapsychic and interpersonal strategies employed by those who focus considerable efforts on maintaining and enhancing their self-esteem (e.g., individuals with fragile high self-esteem or narcissistic personality features). However, those who provide false signals advertising higher levels of self-esteem than they actually possess may be at risk for incurring various costs, including damage to their social reputation. For example, self-enhancers often have impaired social relationships (e.g., Paulhus, 1998), and these individuals may receive negative labels such as haughty, arrogant, vain, or egotistical (Buss, 2004). Future research should examine the maintenance costs that are associated with advertising high levels of self-esteem. Although the potential advantages are readily apparent for "deceiving up" in terms of self-esteem, future research should also examine situations in which individuals may also "deceive down" in an attempt to portray themselves as being of lower status to reduce competition or threat (Hartung, 1987; Sloman \& Gilbert, 2000).

\section{CONCLUSION}

The present studies are consistent with the idea that selfesteem has a status-signaling property such that an individual's level of self-esteem is associated with how others perceive the individual. The results of the present studies found that individuals who had higher levels of self-esteem-or were at least perceived to have higher levels of self-esteem - were generally viewed as possessing more positive personality characteristics than those with lower levels of self-esteem. This was especially true when the perceivers actually knew the targets because this allowed them greater access to information about the targets. The status-signaling model of self-esteem may serve as a complement to previous status-tracking models of self-esteem and suggests the need for an extended informational model of self-esteem in which self-esteem serves as a conduit for the exchange of information between the individual and the social environment.

\section{Note}

1. Additional information concerning the analyses from the present studies is available from the first author upon request. The available information includes tabled descriptions of the results for the regression analysis from Study 1 and the multilevel model from Study 2.

\section{References}

Ames, D. R., \& Bianchi, E. C. (2008). The agreeableness asymmetry in first impressions: Perceivers' impulse to (mis)judge agreeableness and how it is moderated by power. Personality and Social Psychology Bulletin, 34, 1719-1736.

Anderson, M. (1994). Sexual selection. Princeton, NJ: Princeton University Press.

Bergman, D. A., Kozlowski, C. P., McIntyre, J. C., Huber, R., Daws, A. G., \& Moore, P. A. (2003). Temporal dynamics and communication of winner-effects in the crayfish, orconesctes rusticus. Behaviour, 140, 805-825.

Blackman, M. C., \& Funder, D. C. (1998). The effect of information on consensus and accuracy in personal judgment. Journal of Experimental Social Psychology, 34, 164-181.

Blaskovich, J., \& Tomaka, J. (1991). Measures of self-esteem. In J. P. Robinson, P. R. Shaver, \& L. S. Wrightsman (Eds.), Measures of personality and social psychological attitudes (Vol. 1, pp. 115160). New York: Academic.

Bokony, V., Lendvai, A. Z., \& Liker, A. (2006). Multiple cues in status signaling: The role of wingbars in aggressive interactions of male house sparrows. Ethology, 112, 947-954. 
Bryk, A. S., \& Raudenbush, S. W. (1992). Hierarchical linear models: Applications and data analysis methods. Newbury Park, CA: Sage.

Bryk, A. S., Raudenbush, S. W., \& Congdon, R. (1998). HLM for Windows 4.03. Chicago: Scientific Software.

Buhrmester, D., Furman, W., Wittenberg, M. T., \& Reis, H. T. (1988). Five domains of interpersonal competence in peer relationships. Journal of Personality and Social Psychology, 55, 9911008.

Buss, D. M. (1996). Social adaptation and five major factors of personality. In J. S. Wiggins (Ed.), The five-factor model of personality: Theoretical perspectives (pp. 180-207). New York: Guilford Press.

Buss, D. M. (2004). Evolutionary psychology: The new science of the mind. Boston: Pearson.

Campbell, W. K., Rudich, E. A., \& Sedikides, C. (2002). Narcissism, self-esteem, and the positivity of self-views: Two portraits of self-love. Personality and Social Psychology Bulletin, 28, 358368.

Dale, J., Lank, D. B., \& Reeve, H. K. (2001). Signaling individual identity vs. quality: A model and case studies with ruffs, queleas, and house finches. American Naturalist, 158, 75-86.

Estes, R. D. (1992). The behavior guide to African mammals including hoofed mammals, carnivores, primates. Berkeley: University of California Press.

Fossey, D. (1983). Gorillas in the mist. Boston: Houghton Mifflin.

Goffman, E. (1959). The presentation of self in everyday life. New York: Doubleday.

Gosling, S. D., Rentfrow, P. J., \& Swann, W. B., Jr. (2003). A very brief measure of the Big-Five personality domains. Journal of Research in Personality, 37, 504-528.

Grafen, A. (1990). Biological signals as handicaps. Journal of Theoretical Biology, 144, 517-546.

Hartung, J. (1987). Deceiving down: Conjectures on the management of subordinate status. In J. Lockart \& D. L. Paulhus (Eds.), Selfdeception: An adaptive mechanism? (pp. 170-185). Englewood Cliffs, NJ: Prentice-Hall.

Heatherton, T. F., \& Polivy, J. (1991). Development and validation of a scale for measuring state self-esteem. Journal of Personality and Social Psychology, 60, 895-910.

John, O. P., \& Srivastava, S. (1999). The Big Five trait taxonomy: History, measurement and theoretical perspectives. In L. A. Pervin \& O. P. John (Eds.), Handbook of personality: Theory and research (2nd ed., pp. 102-138). New York: Guilford Press.

Jones, E. E., \& Nisbett, R. E. (1971). The actor and observer: Divergent perceptions of the causes of behavior. In E. E. Jones, D. Kanouse, H. H. Kelley, R. E. Nisbett, S. Valms, \& B. Weiner (Eds.), Attribution: Perceiving the causes of behavior (pp. 79-94). New York: General Learning Press.

Kernis, M. H. (2003). Toward a conceptualization of optimal selfesteem. Psychological Inquiry, 14, 1-26.

Kirkpatrick, L. A., \& Ellis, B. J. (2001). Evolutionary perspectives on self-evaluation and self-esteem. In G. Fletcher \& M. Clark (Eds.),
The Blackwell handbook of social psychology: Interpersonal processes (Vol. 2, pp. 411-436). Oxford: Blackwell.

Kurzban, R., \& Aktipis, C. A. (2007). Modularity and the social mind: Are psychologists too self-ish? Personality and Social Psychology Review, 11, 131-149.

Leary, M. R., Tambor, E., Terdal, S., \& Downs, D. L. (1995). Self-esteem as an interpersonal monitor: The sociometer hypothesis. Journal of Personality and Social Psychology, 68, 518-530.

Madon, S., Smith, A., Jussim, L., Russell, D. W., Eccles, J., Palumbo, P., et al. (2001). Am I as you see me or do you see me as I am? Self-fulfilling prophecy and self-verification. Personality and Social Psychology Bulletin, 27, 1214-1224.

Malkin, M. L., Zeigler-Hill, V., Barry, C. T., \& Southard, A. C. (in press). The view from the looking glass: How are narcissistic individuals perceived by others? Journal of Personality, DOI: 10.1111/j.1467-6494.2012.00780.x.

Marcus, D. K., Kashy, D. A., \& Baldwin, S. A. (2009). Studying psychotherapy using the one-with-many design: The therapeutic alliance as an exemplar. Journal of Counseling Psychology, 56, $537-548$.

Martin, J., \& Forsman, A. (1999). Social costs and development of nuptial coloration in male Psammodromus algirus lizards: An experiment. Behavioral Ecology, 10, 396-400.

Myers, E. M., \& Zeigler-Hill, V. (2012). How much do narcissists really like themselves? Using the bogus pipeline procedure to better understand the self-esteem of narcissists. Journal of Research in Personality, 46, 102-105.

Paulhus, D. L. (1998). Interpersonal and intrapsychic adaptiveness of trait self-enhancement: A mixed blessing? Journal of Personality and Social Psychology, 74, 1197-1208.

Paulhus, D. L. (2001). Normal narcissism: Two minimalist accounts. Psychological Inquiry, 12, 228-230.

Paulhus, D. L., Robins, R. W., Trzesniewski, K. H., \& Tracy, J. L. (2004). Two replicable suppressor situations in personality research. Multivariate Behavioral Research, 39, 301-326.

Preuschoft, S. (1999). Are primates behaviorists: Formal dominance, cognition, and free-floating rationales. Journal of Comparative Psychology, 113, 91-95.

Pyszczynski, T., Greenberg, J., Solomon, S., Arndt, J., \& Schimel, J. (2004). Why do people need self-esteem? A theoretical and empirical review. Psychological Bulletin, 130, 435-468.

Raudenbush, S. W., \& Bryk, A. S. (2002). Hierarchical linear models: Applications and data analysis methods (2nd ed.). Newbury Park, CA: Sage.

Robins, R. W., Hendin, H. M., \& Trzesniewski, K. H. (2001). Measuring global self-esteem: Construct validation of a single item measure and the Rosenberg Self-Esteem Scale. Personality and Social Psychology Bulletin, 27, 151-161.

Rosenberg, M. (1965). Society and the adolescent self-image. Princeton, NJ: Princeton University Press

Senar, J. C. (2006). Bird colors as intrasexual signals of aggression and dominance. In G. E. Hill \& K. J. McGraw (Eds.), Bird coloration: Function and evolution (Vol. 2, pp. 125-193). Cambridge, MA: Harvard University Press. 
Shariff, A. F., \& Tracy, J. L. (2009). Knowing who's boss: Implicit perceptions of status from the nonverbal expression of pride. Emotion, 9, 631-639.

Sloman, L., \& Gilbert, P. (2000). Subordination and defeat: An evolutionary approach to mood disorders and their therapy. Mahwah, NJ: Erlbaum.

Soto, C. J., \& John, O. P. (2009). Ten facet scales for the Big Five Inventory: Convergence with NEO PI-R facets, self-peer agreement, and discriminant validity. Journal of Research in Personality, 43, 84-90.

Srivastava, S., \& Beer, J. S. (2005). How self-evaluations relate to being liked by others: Integrating sociometer and attachment perspectives. Journal of Personality and Social Psychology, 89, 966977.

Tesser, A. (2001). On the plasticity of self-defense. Current Directions in Psychological Science, 10, 66-69.

Tibbetts, E. A., \& Dale, J. (2004). A socially enforced signal of quality in a paper wasp. Nature, 432, 218-222.

Tracy, J. L., \& Robins, R. W. (2007). The prototypical pride expression: Development of a nonverbal behavioral coding system. Emotion, 7, 789-801.

Trivers, R. L. (1991). Deceit and self-deception: The relationship between communication and consciousness. In M. Robinson \& L. Tiger (Eds.), Man and beast revisited (pp. 175-191). Washington, DC: Smithsonian.
Watson, D., Suls, J., \& Haig, J. (2002). Global self-esteem in relation to structural models of personality and affectivity. Journal of Personality and Social Psychology, 83, 185-197.

Wiggins, J. S. (1995). Interpersonal Adjective Scales professional manual. Odessa, FL: Psychological Assessment Resources.

Zahavi, A. (1975). Mate selection-A selection for handicap. Journal of Theoretical Biology, 53, 205-214.

Zeigler-Hill, V. (2010). The interpersonal nature of self-esteem: Do different measures of self-esteem possess similar interpersonal content? Journal of Research in Personality, 44, 22-30.

Zeigler-Hill, V., \& Besser A, (2011). Perceivers' self-worth and their attraction to targets with different levels of self-esteem. Unpublished manuscript.

Zeigler-Hill, V., Clark, C. B., \& Beckman, T. E. (2011). Fragile self-esteem and the interpersonal circumplex: Are feelings of selfworth associated with interpersonal style? Self and Identity, 10, 509-536.

Zeigler-Hill, V., \& Myers, E. M. (2009). Is high self-esteem a path to the White House? The implicit theory of self-esteem and the willingness to vote for presidential candidates. Personality and Individual Differences, 46, 14-19.

Zeigler-Hill, V., \& Myers, E. M. (2011). An implicit theory of selfesteem: The consequences of perceived self-esteem for romantic desirability. Evolutionary Psychology, 9, 147-180. 